\title{
editorial
}

\section{Posición de la Sociedad Argentina de Reumatología por el uso del cannabis medicinal}

Los cannabinoides son moléculas que han sido descubiertas el siglo pasado de la planta de la marihuana. En el siglo XX y lo que lleva del XXI, estos productos han sido utilizados predominantemente en carácter recreativo y considerados drogas ilícitas. Es escasa la información del uso médico del cannabis desde el inicio de la era científica; pero en los últimos tiempos, la utilización de derivados de la marihuana para su uso médico ha adquirido relevancia pública y mediática, así como política y jurídica.

En marzo de este año fue aprobada la Ley del cannabis medicinal. Y en septiembre de 2017 fue reglamentada la ley, donde quedaron varios puntos sin definir, pero donde se aclara que el Conicet y el INTA se encargarán del cultivo.

La utilización de los derivados de la marihuana ha tenido una experiencia positiva en algunas afecciones neurológicas en niños, sobre todo en la epilepsia refractaria. En las enfermedades reumáticas, aún no existe suficiente evidencia para su uso.

Por otro lado, no resultan claros los métodos de manufactura, los controles de calidad, las dosis, las vías de administración, así como tampoco se cuenta con estudios de farmacocinética, farmacodinamia, eficacia ni seguridad. Menos aún se cuenta con información de la distribución del producto.

Por lo antedicho, la utilización y la experiencia que se está haciendo con el cannabis medicinal se da principalmente en determinados círculos de pacientes y con médicos y también no médicos, defensores del uso del medicamento a través de experiencias individuales, utilizando productos del cannabis con métodos de producción no estandarizada, sin controles de calidad y, por el momento, fuera de la ley.

Por tales motivos, la Sociedad Argentina de Reumatología no recomienda a los profesionales reumatólogos indicar productos derivados de la marihuana hasta que no se establezcan reglas más claras de producción, estandarización y definiciones farmacoterapéuticas de este tipo de productos. 